\title{
Discussion on the Status of Crowdfunding Industry in China
}

\author{
Yuming Zhang \\ East China University of Political Science and Law \\ Shanghai, China
}

\begin{abstract}
Over the past 40 years of reform and opening up to the outside world, the wisdom of the people is gradually opening up, and the wealth is gradually sufficient. With the maturity of investment strength and desire at present, the "crowdfunding" industry finally "spread to the east" from the west, and gradually presents a blowout trend in the previous years. With the development of this industry, many problems are emerging in the increasingly prosperous crowdfunding market: the risk of investment project failure, regulatory demand for large amount of capital flow... More and more problems not only make investors "fear the repercussions of certain actions", but also make regulators feel scared - it is a question to be answered that how to redefine the crowdfunding industry in China under the gradually tightening market environment.
\end{abstract}

Keywords—crowdfunding; risk; feelings; investment

\section{INTRODUCTION}

As the old saying goes, "When you are in a barn, you know etiquette; when you are well fed, you know honor and disgrace." It is the 41st year since the reform and opening up. Decades of rapid economic development has brought economic prosperity, increasing private capital, and people's demands for continuous growth in the spiritual field. On one hand, for small and medium-sized investors with certain investment capital, they can choose good investment projects to bring wealth to themselves, on the other hand people who have given up their dreams for "survival" are not stingy about investing in young "dreams" that attract their attention with the accumulation of wealth, and within their own capabilities, there are not a few people who have the will to extend a helping hand to the poor and seriously ill. Therefore, in the dual pursuit of feelings and interests, "crowdfunding", a new type of financial form, "floating across the sea", not only takes root in China, but also derives models including equity crowdfunding, debt crowdfunding, incentive crowdfunding and donation crowdfunding.

Why is crowdfunding unstoppable in the Internet era? Why crowdfunding was controversial at its fastest growing stage and began to shrink? It is necessary to find out the reason why crowdfunding was criticized after going to the altar first that the first is to clarify the mechanism behind crowdfunding and the internal factors that drive people to actively participate in crowdfunding, so as to explore the effective regulatory system for crowdfunding platform.

\section{DifFERENT Mode AND CURRENT STATUS OF CROWDFUNDING}

According to different return mode and operation mechanism, there are 4 kinds of crowdfunding mode including pre-sale incentive mode, equity mode, debt mode and donation mode etc. This paper will separately discuss the current status and predicament of crowdfunding mode according to the 4 different types.

\section{A. Incentive Crowding Mode}

The initiations of incentive crowdfunding mainly rely on internet, the information and introduction on the their own products is issued on internet platform, so that the customers who are interest in these products can buy in advance, through which to raise fund for the prior-period investment and follow up development of projects. At present, this mode is mainly used in the directions of cultural creation (such as movies, music, creative products, press and publication etc.) and intelligent electronic products.

Taking "Kaistart" as an example, as a crowdfunding platform, it mainly focus on "Lifestyle mode" investment project, in the list of projects, cultural industries such as characteristic accommodation, creative catering and cultural innovation occupy the main part. As the founder of the platform once served as the editor in chief of the Daily News, the platform mixed the characteristics of media and finance. Each project on the platform is processed by the editing team to form a promotional article similar to the news manuscript, which combines pictures and videos, and is divided into different levels of return according to the different amount of money invested, so that the subscribers can enjoy different rewards such as hotel residence, cultural creative use, restaurant experience, etc. For this kind of investors, except for the promise that a few projects have a fixed dividend, the vast majority prefer to buy and sell in advance, therefore, in this kind of crowdfunding mode, "feelings" seems to be the main selling point compared with the interests.

As the slogan put forward at the beginning of Kaistart -"This is the way that you retaliate mediocrity", Kaistart takes the "sense of participation" as its attracting point at the beginning, "the core of sense of participation is transparent, the users are totally transparent during the whole process, and know the value of transparency, and there are requirement connection between the fund holders and the 
project parts, but it is not a pure requirement of fund, sometimes it is consumers' needs, social needs and even the requirements of career", it's not hard to see that behind the economic benefits, what actually supports most users of the platform is the pursuit of feelings. In terms of the accommodation projects with the highest proportion of the platform, most of the projects are based on the traditional pursuit of "slow", "nature", "Zen", etc., and the financing rate of the projects is even higher than $4000 \%$-- media packaging and crowdfunding platform of science and technology cooperate with each other, attracted a number of investors in the gap to survive through the new era of online advertising and fund-raising platform.

However, for those who are driven by feelings, once the final product is not in line with their own expectations, there will be a "trust crisis" between them. In terms of the game industry, the classic sequel Mighty No. 9 was once placed high hopes by fans. With the presence of the father of Mega Man, Keiji Inafure, the crowdfunding project not only quickly completed the financing goal of $\$ 900,000$, but also successfully raised nearly $\$ 4$ million to develop the game. However, this game attracted thousands of attention by relying on feelings finally became the negative model of "selling feelings" — the development progress was not smooth, the sale of the game was delayed, and many crowdfunding commitments were either delayed or ignored. While the game became a mediocre work, the reputation of its creators and the company suddenly turned down, too. After many similar promises failed, it seems that foreign gamers have lost interest in game crowdfunding According to the data, KickStarter's video game fund-raising fell by nearly $6 \%$ in 2016 compared with 2015, and a sharp decline that has not been seen since the establishment of the website in 2009. Coincidentally, the total profitability of crowdfunding successful games has dropped by nearly $60 \%$, from $\$ 41$ million in 2015 to $\$ 17$ million in 2016. On the premise that the number of successful crowdfunding games has not changed greatly, the average revenue to each game has declined significantly.

It's not hard to see that when the "power generation for love" investors find their feelings are deceived, they will have a natural separation or even exclusion for similar projects and projects of the same sponsor. Compared with the interest driven investors, the sentiment driven investors are often faced with the double betrayal of emotion and interest. If this is not effectively regulated, it will not only degrade people's enthusiasm for participation in incentive crowdfunding projects, but also the original industry will be controversial because of the emotion of investors.

\section{B. Donation Crowdfunding Mode}

Different from the other three kinds of crowdfunding, which belong to the investment mode of economic return, donation crowdfunding actually has the same essence as traditional charity fundraising. Crowdfunding people are eager to help and realize their self-worth because they have sympathy and even some resonance with the sponsor's experience. Therefore, they provide economic assistance to the sponsor's projects out of the original intention of love -- it is not so much an investment as a love giving mechanism in the new era.

Different from the common sense of love giving, the donation type of crowdfunding is usually for a special project. When the donation is initiated, the sponsor will inform the potential investors of the amount of this crowdfunding and its future flow; in order to increase the credibility of the project and attract investors to be more confident in the higher amount of fund-raising, the platform, as an unofficial organization, will often assume the responsibility of supervision to carry out follow-up reports on the project through continuous tracking, release certification and other ways. Due to the non-profit purpose of the donation crowd funding participants, different from the monetary return, such investors are more inclined to obtain emotional feedback and satisfaction, or an intrinsic value and identity. As for the nature of this kind of crowdfunding contract, some scholars put forward the view of "adding obligation donation contract" - That is to say, when the project is launched, the fundraiser has the obligation to explain the real situation, provide relevant vouchers, and explain the purpose of crowdfunding, and continues to have a reporting obligation in the subsequent use of funds. By displaying the above obligations, the sponsor makes an offer to the participants, who will learn about the project and make donations on the crowdfunding platform.

However, just like the common fault of online fundraising, the endless "fraudulent donation" events are consuming the original fervent kindness of the people. Different from the strict auditing mechanism in traditional charity, in the Internet era, the current crowdfunding platform relies more on browsing amount to attract public attention. Medical records, testimonies and other materials must be provided as necessary evidence, but the criteria for the public to decide whether to donate or not is still the subjective factor in their hearts--whether the feelings are sincere enough, whether the experience is tragic enough, whether it can arouse the sympathy of publics, etc., these subjective standards also lead to the situation that false information is easily accepted.

However, once the donors find that their love is abused, they are prone to conflict and hate, and false information will reduce the trust of the whole society in donation crowdfunding, Guo Meimei, once a national sensation, makes the Red Cross still controversial today, which may be a lesson from the past. Therefore, in fact, China has adopted relatively strict supervision on the crowdfunding platform itself, which requires that donation crowdfunding must pass the relevant qualified platform, and prohibit publishing information as an individual. However, due to the low threshold of crowdfunding projects and the virtual nature of the Internet itself, there are still many behaviors such as false medical records and different standards.

A few days ago, Wu Heshen of Deyunshe launched a crowdfunding with a total amount of millions on Shuidi crowdfunding platform, later, its property, such as two suites and cars, was exposed one after another, and the contrast between wealth and crowdfunding donations aroused public 
indignation. Although his wife and the founder of Shuidi crowdfunding platform explained one after another, the netizens were still "indignant". Obviously, the original intention of donation crowdfunding is to rescue. For the serious illness crowdfunding platforms such as Shuidi crowdfunding, the public expects the purpose of the fund to be "saving lives" rather than maintaining the existing living standards of the financiers. Therefore, when the public's expectations are quite different from the reality, it is inevitable to generate anger. In addition, after the fermentation of this event, the society has raised doubts about the audit standard of Shuidi crowdfunding. However, from the perspective of crowdfunding platform, its unofficial identity makes it lack of justifiable reasons to audit the assets of the sponsor, it can only test medical records, testimonies, bills and other methods that are more prone to fraud to prove the sponsor's information.

Therefore, balancing the responsibilities of the platform and the expectations of the public is the urgent task of the current regulatory thinking.

\section{Equity Crowdfunding Mode}

At present, the main business of equity crowdfunding is to serve start-ups, especially in mobile internet, e-commerce, mobile PC, real estate and other enterprises. However, in addition to risk management and control, the development of equity crowdfunding in offline China is faced with legal embarrassment. Because the development of China's financial market starts later than that of foreign countries, internet finance is also in the primary development stage. With the strict control of financial market risks, China's financial market is not fully market-oriented at present. Therefore, as soon as equity crowdfunding appears, it is faced with the problem of "legal and illegal vague boundaries". In 2013, the first equity crowdfunding case appeared in China, and the next year, China ushered in the first secured equity crowdfunding project. In May of the same year, China Securities Regulatory Commission issued a draft of opinions aimed at crowdfunding supervision. Half a year later, the executive meeting of the State Council proposed to develop the pilot of small amount crowdfunding in the capital market. In December of this year, China Securities Association issued The Regulation of Private Equity Crowdfunding (Trial) (Draft for Comments). In 2015, the general office of the State Council issued the guidance on The Development of Crowdfunding Space to Promote Mass Innovation and Entrepreneurship. When the opinions on economic reform were approved during the two sessions of China, the "pilot of equity crowdfunding" was proposed again. In July of the same year, ten ministries and commissions defined "equity crowdfunding" in The Guidance on Promoting the Healthy Development of Internet Finance, and on August 3, CSRC issued a notice on special inspection of relevant institutions. It is not hard to see that from 2012 to 2015, equity crowdfunding in China is gradually moving towards the direction of standardization and legalization.

Equity crowdfunding has many advantages, such as low threshold, low cost and high efficiency. It also provides a new way for many new-type enterprises and small and medium-sized enterprises when the traditional financing channels are blocked. However, with the continuous development of equity crowdfunding, its disadvantages are increasingly prominent. Until now, the situation of equity crowdfunding is still in a chaos state. Although the number of crowdfunding platforms has increased, the volume of transactions is low. At the same time, the investor positioning of some crowdfunding platforms has seriously deviated from the proper track, focusing on the elderly with weak risk awareness and lack of investment ideas and judgment standards. In addition, considering the lack of accurate recognition of risk and market by large groups of investors in China at present, the state should also strengthen the training of investors, improve risk awareness, establish correct investment concept, guide the market concept of "buyers should be responsible for the risk", and emphasize that the essence of equity crowdfunding is private equity financing, which is an investment project with risk of failure, so as to weaken or even eliminate the excessive expectations of the people for rigid cashing.

\section{Debt Crowdfunding Mode}

Debt financing mainly refers to the financing behavior that both parties with investment and financing needs directly borrow through the internet platform. When the project is due, the investor shall recover the principal and interest. It is a point-to-point financing method. In China, debt crowdfunding is more recognized in the way of "P2P network lending" in practice. For debt crowdfunding, China is still in the initial stage of legislation. Indeed, in order to encourage financial innovation and promote the healthy development of internet finance, debt crowdfunding should be supported by legalization. However, it is more important to clarify the responsibility of supervision and regulate the market order. Recently, the people's Bank of China, China Banking Regulatory Commission and other departments have jointly issued The Guidance on Promoting the Healthy Development of Internet Finance, which has a guiding role in the division of regulatory responsibilities. At present, due to the natural risks such as moral risk and system risk, as well as some negative cases of abscond with money, people have been cautious about the investment of debt crowdfunding. Therefore, it is necessary to strengthen the third-party deposit of customer funds, strengthen information disclosure to protect small and medium-sized investors. Considering the particularity of the internet era, relevant departments should strengthen the self-discipline of the internet financial industry through systems like data monitoring, credit rating and so on. However, at present, the regulation of laws and regulations in China is still relatively broad, and only the principle regulation is made. For the lack of specialized and specific laws and regulations for the online lending crowdfunding platform, the regulatory role of relevant departments needs to be discussed. Therefore, for debt financing, it has become a problem that must be considered in the current financial system reform that how to control risks, dispel investors' doubts, activate the private market, strengthen the supervision of the platform at the 
same time, and avoid illegal fund-raising, money laundering, fraud and other acts.

\section{CONCLUSION}

In fact, the rapid development of crowdfunding industry is accompanied by the most brilliant and vigorous period of economic development in China. The private assets are abundant and the investment enthusiasm is high. Driven by the double drive of interests and feelings, the crowdfunding industry can develop rapidly. However, with China's economy development is lower than the GDP of China, as well as the bottleneck faced by the industry at a certain stage of development, the development of crowdfunding industry in China has exposed many problems, and the lack of risk management and control has become increasingly obvious. It is undeniable that although the industry is under strict supervision, China has not achieved a complete and systematic regulation from the legal system. In practice, the risk is only monitored through the administrative means of relevant departments, and the platform is not provided with necessary assistance and centralized management to establish an industry self-governance organization. All of there have caused the difficulties for crowdfunding mistrust of the publics, difficulty in controlling risks and vague legal nature...Therefore, in order to solve the above problems, it is necessary to firstly improve the relevant legal system, then strengthen the industry control and standardize the platform responsibility, so as to realize the protection of small and medium-sized investors. In this way, it can help the healthy development of crowdfunding industry and provide a solution for the financing of small and micro enterprises in China. Only in this way, people's confidence in investment can be rekindled, and the investment decisions made by them out of feelings or interests will not be lived up.

\section{REFERENCES}

[1] Shi Hongwei Research on Legal Risk and Regulation of Debt Crowdfunding in China, Master Degree Thesis, 06/2017. (in Chinese)

[2] Liu Zhijian, Wu Ke The Origin, Development and Prospect of Crowdfunding, Hainan Finance, the 6th issue in 2014. (in Chinese)

[3] $\mathrm{Hu}$ Xiaoqi, Chen Xueru Research on Internet Equity Crowdfunding Risk from the Perspective of Information Asymmetry, Modern Management Science, the 4th issue in 2019. (in Chinese)

[4] Zhang Mingjing Legal Nature and Risk of Donation Crowdfunding, Legality Vision, 09/2018, Volume II. (in Chinese)

[5] Yi Yan Research on Legal Problems of Investors' Right Protection in Debt Crowdfunding, Doctor Degree Thesis, 05/2016. (in Chinese) 